\title{
Fresh properties of HPSCC containing SRA and expansive admixtures
}

\author{
Ronaldo Pilar ${ }^{1}$, Raissa Douglas Ferron ${ }^{2}$, \\ Wellington Longuini Repette ${ }^{3}$
}

\author{
${ }^{1}$ Departamento de Engenharia Civil, Universidade Federal do Espírito Santo - UFES, Av. Fernando Ferrais 514, Goia- \\ beiras, CEP 29075-910 Vitória, ES, Brasil. \\ ${ }^{2}$ Department of Civil, Architectural and Environmental Engineering, The University of Texas at Austin - Austin, TX - \\ USA \\ ${ }^{3}$ Departamento de Engenharia Civil, Universidade Federal de Santa Catarina - UFSC, Rua João Pio Duarte Silva 250, \\ Córrego Grande, CEP 88040-900 Florianópolis, SC, Brasil. \\ e-mail: ronaldo_pilar@hotmail.com; wellington.repette.@gmail.com
}

\begin{abstract}
Shrinkage-reducing admixture (SRA) and expansive admixture (EXA) were used in high performance selfcompacting concrete (HPSCC) to mitigate autogenous shrinkage. In order to evaluate the fresh properties of concretes, the rheological parameters were determined in a ICAR rheometer at 10, 25, 40, 60 and 90 min. The flow behavior of the mixtures was described by Bingham, Herschel-Bulkley, and modified Bingham models. Slump flow test, V-funnel test and J-Ring test were also carried out at $10 \mathrm{~min}$. Slump flow test was performed also after $90 \mathrm{~min}$ of mixing. The test results showed that, at 10 minutes, all mixtures had similar performances, independently of the SRA and EXA contents. However, the slump flow test shows a reduction of up to $24 \%$ of its diameter at 90 min for mixtures with EXA. Mixtures with EXA revealed a gradual increase in dynamic yield stress with elapsed time. In contrast, concretes with SRA exhibited less variation in its rheological properties. Statistical analysis (ANOVA) showed that, regardless of the rheological model adopted, the admixture content was not a significant factor for the yield stress, while the type of admixture and the time of testing greatly influenced the concretes rheological response.
\end{abstract}

Keywords: Shrinkage-reducing admixture (SRA), expansive admixture (EXA), rheological behavior, high performance self-compacting concrete.

\section{INTRODUCTION}

High performance self-compacting concrete (HPSCC) is a type of concrete that has been developed to exhibit high flowability and mix stability and, at the same time, high strength and durability [1,2]. Higher amounts of Portland cement, superplasticizer, and mineral admixtures, together with low water/binder ratios are used to produce these concretes. Thus, the HPSCC has low porosity and discontinuous small diameter capillary pore structure of the hydrated paste $[3,4]$. Consequently, HPSCC has potential to present more pronounced autogenous shrinkage than normal concrete, mainly at early ages [4,5]. Therefore, cracks due to restrained autogenous shrinkage can compromise the concrete's performance, despite of HPSCC's high strength and durability. To avoid the aforementioned problems, shrinkage-reducing admixtures (SRA) or expansive admixtures (EXA) can be used for shrinkage mitigation.

Expansive admixtures are agents that produce expansion by the release of gases or by ettringite formation [6,7]. Calcium sulfoaluminate (CSA) based expansive admixtures are mostly used when the focus is to compensate for shrinkage of concrete [6-8]. Usually, CSA admixtures comprise an aluminum bearing material, hydrated and free lime, and gypsum, carefully proportioned to promote the controlled (timing and amount) formation of ettringite acicular crystals $\left(3 \mathrm{CaO} \cdot \mathrm{Al}_{2} \mathrm{O}_{3} \cdot 3 \mathrm{CaSO}_{4} \cdot 32 \mathrm{H}_{2} \mathrm{O}\right)$ [7,9]. On the other hand, the shrinkage-reducing admixture acts by reducing the surface tension of concrete pores solution and, consequently, reducing the capillary stress. This approach is clear when one analyses the Young-Laplace equation $\left((1)\right.$, where the surface tension is directly proportional to the capillary stresses. In this equation $\sigma_{\text {cap }}$ is the capillary tension $(\mathrm{Pa}), \gamma_{\mathrm{lg}}$ is the surface tension of the pore solution $(\mathrm{N} / \mathrm{m}), \theta$ is the contact angle between the pore solution and the capillary pore walls and $r$ is the meniscus radius $(\mathrm{m})[10,11]$. The main molecules used as shrinkage-reducing admixtures are glycols, polyoxyalkylene glycol alkyl esthers, polymeric surfactants 
and amino alcohols with various surfactants [12].

$$
\sigma_{\text {cap }}=\frac{2 \gamma_{l g} \cos \theta}{r}
$$

Although the action of SRA and EXA in the hardened state of concrete has been investigated, little is known about the plastic stage [6,7,11,13-17]. Measurements of workability are essential to guarantee a good quality of concrete and the ease with which the mixture is processed [18]. Tests such as the Abrams cone for traditional concrete or the slump flow test for self-compacting concrete (SCC) are still the chosen everyday tests to quantify the workability of cementitious materials at the building site. Empirical test methods are used to give some kind of rheological description of the fresh concrete, such as slump flow, L-box and Vfunnel [19]. However, these tests are very often operator-sensitive [20,21]. Viscometers and advanced rheometers are usually designed to be operatively insensitive and, consequently, retrieve the material's parameters in terms of fundamental physical quantities independent on the details of the apparatus with which they are measured [19]. This way, rheology can be used as a tool to accurately describe the workability of selfcompacting concrete by its flow curves.

The commonly used rheological models to describe the flow behavior of fresh cementitious material are the Bingham model, the Herschel-Bulkley model, and the modified Bingham model [22-26], which have been used commonly to described viscoplastic fluids [27]. For viscoplastic fluids, at stresses below the yield stress, the shear rate is null, causing the rheological model to intersect the stress axis above the origin [28]. In other words, these materials do not show appreciable deformation until the shear stress has reached the limit, called the yield stress [27]. Table 1 gives the equations of the rheological models abovementioned. It can be observed that Bingham equation is linear. Herschel-Bulkley is a non-liner model and the exponent ' $n$ ' can be $\mathrm{n}<1, \mathrm{n}>1$, or $\mathrm{n}=1$, signifying a shear thinning behavior, shear thickening behavior or the Bingham model, respectively [19]. Analogously, the modified Bingham is also a non-liner model which indicates a shear thinning behavior, shear thickening, or the Bingham model when $c / \mu<0, \mathrm{c} / \mu>0$, or $\mathrm{c} / \mu=0$, respectively [29].

Table 1: Rheological models.

\begin{tabular}{|c|c|}
\hline EQUATION NAME & EQUATION \\
\hline Bingham & $\tau=\tau_{0}+\mu_{p} \dot{\gamma}$ \\
\hline Herschel-Bulkley & $\tau=\tau_{0}+K \dot{\gamma}^{n}$ \\
\hline modified Bingham & $\tau=\tau_{0}+\mu \dot{\gamma}+c \dot{\gamma}^{2}$ \\
\hline \multicolumn{2}{|l|}{ Variable definitions } \\
\hline$\tau=$ Shear stress $(\mathrm{Pa})$ & $\mathrm{k}=$ Consistency factor $\left(\mathrm{Pa} . \mathrm{s}^{\mathrm{n}}\right)$ \\
\hline$\tau_{0}=$ Yield stress $(\mathrm{Pa})$ & $\mathrm{n}=$ Consistency index \\
\hline$\mu_{\mathrm{P}}=$ Plastic viscosity (Pa.s) & $\mu=$ Linear term (Pa.s) \\
\hline$\dot{\gamma}=$ Shear rate $\left(\mathrm{s}^{-1}\right)$ & $c=$ Second order term $\left(\mathrm{Pa}_{\mathrm{s}} \mathrm{s}^{2}\right)$ \\
\hline
\end{tabular}

Thus, in this paper, fresh state HPSCC mixes with one shrinkage reducing admixture and one expansive admixture were evaluated. For the present study, concrete rheometer ICAR and empirical tests for selfcompacting concrete (slump flow, V-funnel, J-ring) measurements were carried out. The second part of this study will be an analysis about the hardened properties of these concretes.

\section{EXPERIMENTAL PROGRAM}

Portland cement CP V (PC), according to Brazilian normalization NBR 5733/91 (similar to type III - ASTM $\mathrm{C} 150 / 16)$, was used in all the mixtures. A commercially available Type $\mathrm{F}$ polycarboxylate superplasticizer (SP) was used, conforming to ASTM C 494/16. The solid concentration of the admixture was reported by the manufacturer to be $30 \%$ and the specific gravity, 0.91 . In order to reduce the autogenous deformation, a hexylene glycol based shrinkage reducing admixture (SRA) and a calcium sulfoaluminate based expansive admixture (EXA) were studied. The specific gravity of the SRA was reported by its manufacturer to be 0.92 . EXA consists of hauyhe (3CaO.3Al2O3.CaSO4), free lime $(\mathrm{CaO})$, and anhydrite $(\mathrm{CaSO} 4)$. The physical and chemical properties of the solid materials used are reported in Table 2 and Figure 1. FTIR spectrums of the superplasticizer and SRA are shown in Figure 2. 
Table 2: Physical properties and chemical composition of solid materials.

\begin{tabular}{|c|c|c|c|c|c|c|c|c|c|}
\hline \multirow{2}{*}{ MATERIAL } & \multicolumn{2}{|c|}{ PHYSICAL PROPERTIES } & \multicolumn{7}{|c|}{ CHEMICAL COMPOSITION } \\
\hline & Specific gravity & Fineness, $\mathrm{m}^{2} / \mathrm{kg}$ & $\mathrm{SiO}_{2}$ & $\mathrm{Al}_{2} \mathrm{O}_{3}$ & $\mathrm{Fe}_{2} \mathrm{O}_{3}$ & $\mathrm{CaO}$ & $\mathrm{MgO}$ & $\mathrm{SO}_{3}$ & LOI \\
\hline Cement & 3.09 & 407 & 18,9 & 3,7 & 2,8 & 62,9 & 4,2 & 3,1 & 3,2 \\
\hline Silica & 2.22 & - & 94,6 & $<0,04$ & 0,1 & 0,2 & 0,3 & 0,1 & 2,7 \\
\hline EXA & 3,01 & 374 & 1,8 & 4,7 & 1,3 & 68,5 & 0,9 & 18,2 & 4,4 \\
\hline
\end{tabular}

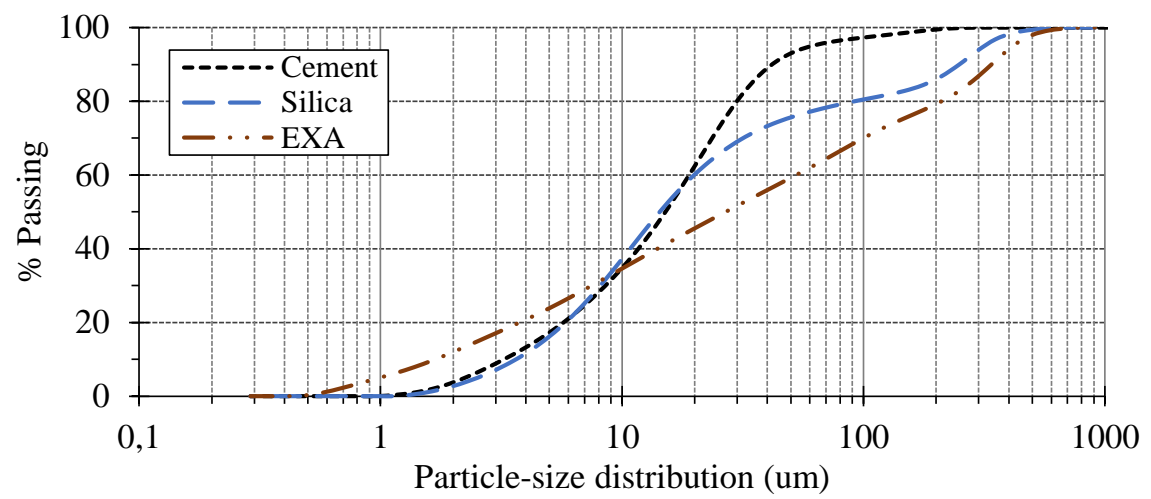

Figure 1: Laser particle size distribution of Portland cement, silica fume and EXA.

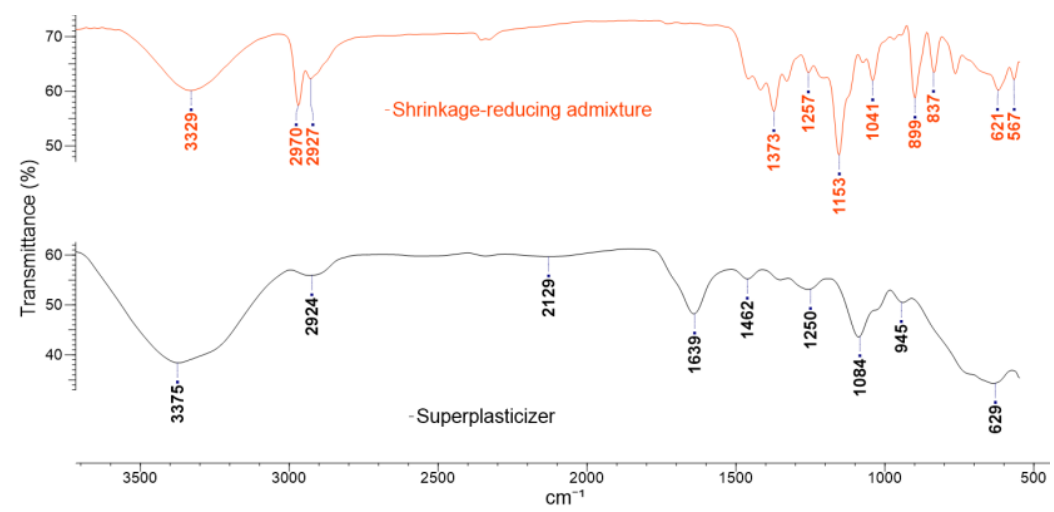

Figure 2: FTIR spectrums of SRA and superplasticizer.

\subsection{Concrete mixture proportions}

To evaluate the rheological behavior of HPSCC containing SRA and EXA, 7 mix proportions were designed. All the concretes were designed with the same volume of cement paste $\left(455 \pm 1 \mathrm{l} / \mathrm{m}^{3}\right)$, fine aggregate $(195 \pm$ $\left.1 \mathrm{l} / \mathrm{m}^{3}\right)$, and coarse aggregate $\left(350 \pm 1 \mathrm{l} / \mathrm{m}^{3}\right)$. The binder was a composition, by mass, of $10 \%$ silica fume (SF) and $90 \%$ Portland cement. The mixtures were designed with a water/binder $(\mathrm{w} / \mathrm{b})$ ratio of 0.32 . Three different dosages of SRA $(0.5 \%, 1.0 \%$, and $1.5 \%)$ and EXA $(5 \%, 10 \%$, and $15 \%)$ were used. The percentage of the admixtures are given by Portland cement mass. The SRA was added as a partial replacement of the mixing water. The dosage of the EXA was calculated as a partial replacement of the Portland cement. To achieve a slump flow between 65 and $70 \mathrm{~cm}$, different superplasticizer contents were added. The summary of mixture proportions is listed in Table 3. 
Table 3: Mixture proportions of the HPSCC.

\begin{tabular}{lccccccccc}
\hline \multirow{2}{*}{ Concrete ID } & w/b & Cement & SF & $\begin{array}{c}\text { Fine } \\
\text { aggregate }\end{array}$ & $\begin{array}{c}\text { Coarse } \\
\text { aggregate }\end{array}$ & Water & SP & EXA & SRA \\
\cline { 3 - 9 } & & \multicolumn{7}{c}{$\left(\mathrm{kg} / \mathrm{m}^{3}\right)$} \\
\hline REF & 0,32 & 630 & 70 & 511 & 922 & 224 & 4,47 & - & - \\
SRA32-0.5 & 0,32 & 630 & 70 & 511 & 922 & 221 & 5,22 & - & 3,1 \\
SRA32-1.0 & 0,32 & 630 & 70 & 511 & 922 & 218 & 4,91 & - & 6,3 \\
SRA32-1.5 & 0,32 & 630 & 70 & 511 & 922 & 215 & 4,39 & - & 9,4 \\
EXA32-5 & 0,32 & 598 & 70 & 511 & 922 & 224 & 4,58 & 31,5 & \\
EXA32-10 & 0,32 & 567 & 70 & 511 & 922 & 224 & 4,95 & 63,0 \\
EXA32-15 & 0,32 & 535 & 70 & 511 & 922 & 224 & 5,27 & 94,5 \\
\hline
\end{tabular}

\subsection{Mixing and tests performed}

The solid materials were dry mixed for about $30 \mathrm{~s}$ inside of the mixer. Then, after dissolving the SP and SRA in water, when present in the mixture, they were added to the mix. All concretes were mixed for 5 min and kept 3 min resting, then again mixed for more $1 \frac{1}{2} \mathrm{~min}$. After 10 minutes of the addition of water, the slump flow diameter, J-ring diameter and V-funnel flow time tests were conducted simultaneously, regarding ASTM C1611 [30], ASTM C 1621 [31], and EFNARC [32], respectively. The slump flow test was also performed after 90 minutes to check the retention of workability.

The filling ability and stability of self-compacting concrete in the fresh state can be defined by four critical characteristics: flowability, viscosity, passing ability and segregation resistance [32]. The slump flow test is used to monitor the consistency of fresh self-compacting concrete and its unconfined flow potential [30]. Slump flow value is the primary check that the fresh concrete consistence meets the specification

[32]. The J-ring is a strong contender for the evaluation of passing ability of self-compacting concrete

[31]. HPSCC's viscosity can be assessed by V-funnel flow time. Although the direct viscosity cannot be measured, the time value is related by describing the filling ability [32].

An ICAR rheometer with four blades-vane with a diameter, $d$, of $127 \mathrm{~mm}$ and height, $h$, of $127 \mathrm{~mm}$ was used to measure the rheological behavior of HPSCC. The container with $300 \mathrm{~mm}$ diameter was filled with fresh concrete up to a height of $280 \mathrm{~mm}$. The inner wall of the container is equipped with ribs to prevent slippage between the concrete and the steel surface [33]. Each concrete sample was pre-conditioned with a shear of 0.5 rotation per second (rps) for a breakdown period of $20 \mathrm{~s}$. Torque measurements were recorded for seven speeds in descending order every $5 \mathrm{~s}$, ranging from 0.5 to 0.05 rps. Flow curves (torque and rotational velocity) were obtained at 10, 25, 40,60 and 90 min after mixing begins.

\subsection{Rheological approach}

Three models were used to analyze the rheological response of the fresh concrete: Bingham, HerschelBulkley and modified Bingham. For the Bingham model, the data for each time was fitted to a linear equation using ordinary least square regression to determine a slope and an intercept point, according to (2. In this equation $G_{B}$ is the point of intersection of the line with the torque axis (N.m), and relates to the yield stress; $H_{B}$ represents the slope of the line (N.m/rps), and is related to the plastic viscosity; $T$ is the torque (N.m); $N$ is the rotational speed $\left(\mathrm{rev.s}{ }^{-1}\right)$ [29]. The term yield stress, according to the Bingham model, is referred as the dynamic yield stress, since this parameter is only correctly characterized when the material is at a steady state in the range of the evaluated shear rate interval [34].

In order to study the rheological behavior by the Herschel-Bulkley model ( (3), experimental steady state data, for each time, was determined by a nonlinear least square curve fitting, where $G_{H B}$ is flow resistance (N.m); $H_{H B}$ is the viscosity factor $\left(\mathrm{N} . \mathrm{m} / \mathrm{rps}^{\mathrm{J}}\right)$; and $J$ is the flow index factor. In the same way, for the modified Bingham model, $G_{m B}, H_{m B}$, and $C_{m B}$ are respectively the flow resistance (N.m), first order term $(\mathrm{N} . \mathrm{m} / \mathrm{rps})$ and second order term $\left(\mathrm{N} \cdot \mathrm{m} / \mathrm{rps}^{2}\right)$.

$$
\begin{aligned}
& T=G_{B}+H_{B} N \\
& T=G_{H B}+H_{H B} N^{J}
\end{aligned}
$$


$T=G_{m B}+H_{m B} N+C_{m B} N^{2}$

Reiner-Riwlin equation for Bingham materials can be used as follows in the equations ( 5 and ( 6 to determine the plastic viscosity (Pa.s) and dynamic yield stress $(\mathrm{Pa})$, respectively $[26,35,36]$. Although it does not provide a point-to-point transformation, it expresses the obtained relation in fundamental units [37], where $h$ is the height $(\mathrm{m})$ of the cylinder submerged in the concrete, $R_{l}$ is the vane radius (m) and $R_{0}$ is the outer container radius $(\mathrm{m})$. Similarly, the Herschel-Bulkley and modified Bingham fundamental rheological parameters were determined by Equations $(7,(8,(9$ and $(10,(11,(12$, respectively $[26,35]$.

$$
\tau_{0}=\frac{G_{B}}{4 \pi h \ln \left(\frac{R_{0}}{R_{i}}\right)}\left(\frac{1}{R_{i}^{2}}-\frac{1}{R_{0}^{2}}\right)
$$

$$
\mu_{p}=\frac{H_{B}}{8 \pi h}\left(\frac{1}{R_{i}^{2}}-\frac{1}{R_{0}^{2}}\right)
$$

$$
\tau_{0}=\frac{G_{H B}}{4 \pi h}\left(\frac{1}{R_{i}^{2}}-\frac{1}{R_{0}^{2}}\right) \frac{1}{\ln \left(\frac{R_{0}}{R_{i}}\right)}
$$

Herschel-Bulkley

$$
k=\frac{H_{H B}}{2^{2 n+1} \pi^{n+1} h} n^{n}\left(\frac{1}{R_{i}^{2}}-\frac{1}{R_{0}^{2}}\right)^{n}
$$

$n=J$

$$
\tau_{0}=\frac{1}{4 \pi h} \frac{G_{m B}}{\ln \left(\frac{R_{0}}{R_{i}}\right)}\left(\frac{1}{R_{i}^{2}}-\frac{1}{R_{0}^{2}}\right)
$$

modified Bingham

$$
\begin{aligned}
& \mu=\frac{H_{m B}}{8 \pi^{2} h}\left(\frac{1}{R_{i}^{2}}-\frac{1}{R_{0}^{2}}\right) \\
& c=\frac{\frac{1}{R_{i}^{2}}-\frac{1}{R_{0}^{2}}}{8 \pi^{3} h} \frac{\left(R_{0}-R_{i}\right)}{\left(R_{0}+R_{i}\right)} C_{m B}
\end{aligned}
$$

The measurements of rheological parameters for fresh concretes were performed without repetition. However, complementary studies were performed previously to verify the variation of the measurements. The maximum average relative standard deviation for dynamic yield stress was of $6 \%$. Analysis of variance (ANOVA) was used to determine the significance of the factors evaluated to achieve the rheology parameters.

\section{RESULTS AND DISCUSSION}

The HPSCC mixes produced in this study had the slump flow diameter at 10 minutes varying between 650 $\mathrm{mm}$ and $690 \mathrm{~mm}$, as shown in Table 3 and Figure 3. However, to reach these values of slump flow diameter, the SRA32-0,5 and EXA32-15 mixes demanded higher amounts of superplasticizer, 5.22 and $5.27 \mathrm{~kg} / \mathrm{m}^{3}$, respectively. The results of V-Funnel and J-Ring tests of the HPSCC mixtures evaluated are shown in the Figure 4. The V-funnel flow time varied between 5 and $6.5 \mathrm{~s}$ for all mixtures, which projects good filling ability even with congested reinforcement [32]. SRA and EXA contents marginally affects J-ring values and V-funnel flow times. In general, empirical test results showed that all mixtures had similar performances at 10 minutes, independently of SRA and EXA contents. However, the slump flow test shows a reduction of up to $24 \%$ of its diameter at $90 \mathrm{~min}$ for mixtures with EXA, which is higher than the observed in the reference and SRA mixtures. The difference between slump flow and J-Ring flow results were between 5 and $7 \mathrm{~cm}$. This can represent noticeable blockage which means a low passing ability of these mixtures. Deference higher than $5 \mathrm{~cm}$ are considered as extreme blocking [31], although these J-Ring values are reported for HPSCC [38-40]. Based on 90-minute slump flow results, all mixtures can be classified as SCC [32]. 


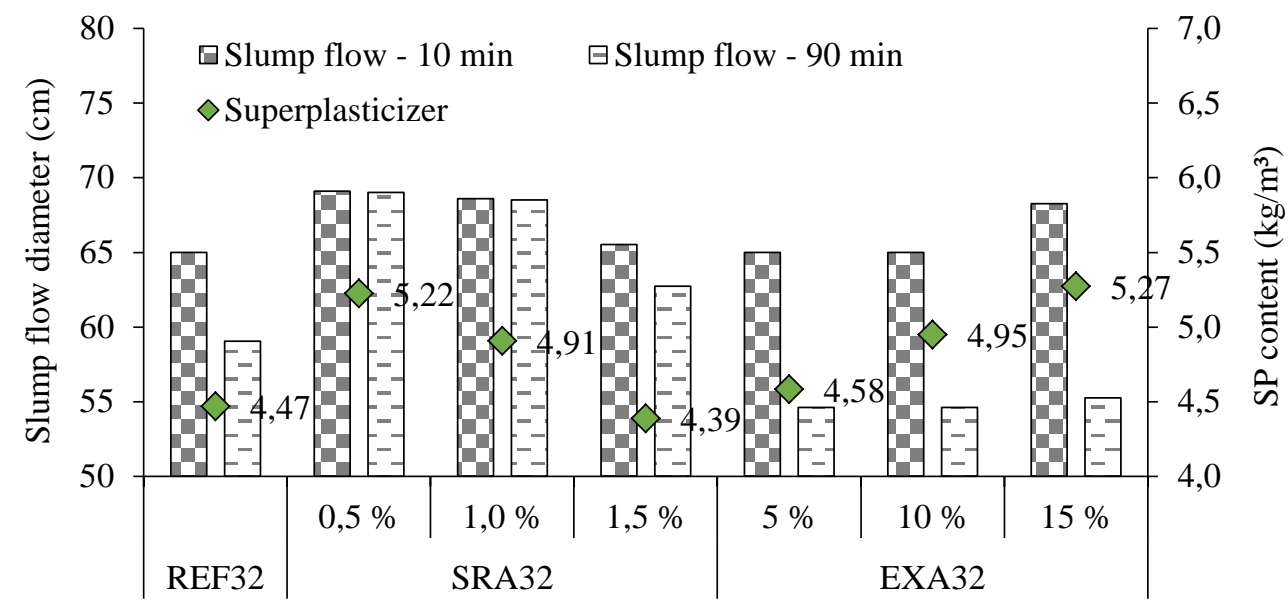

Figure 3: Variation of SP content and Slump flow test with 10 and 90 min of HPSCC with SRA, EXA, and Reference.

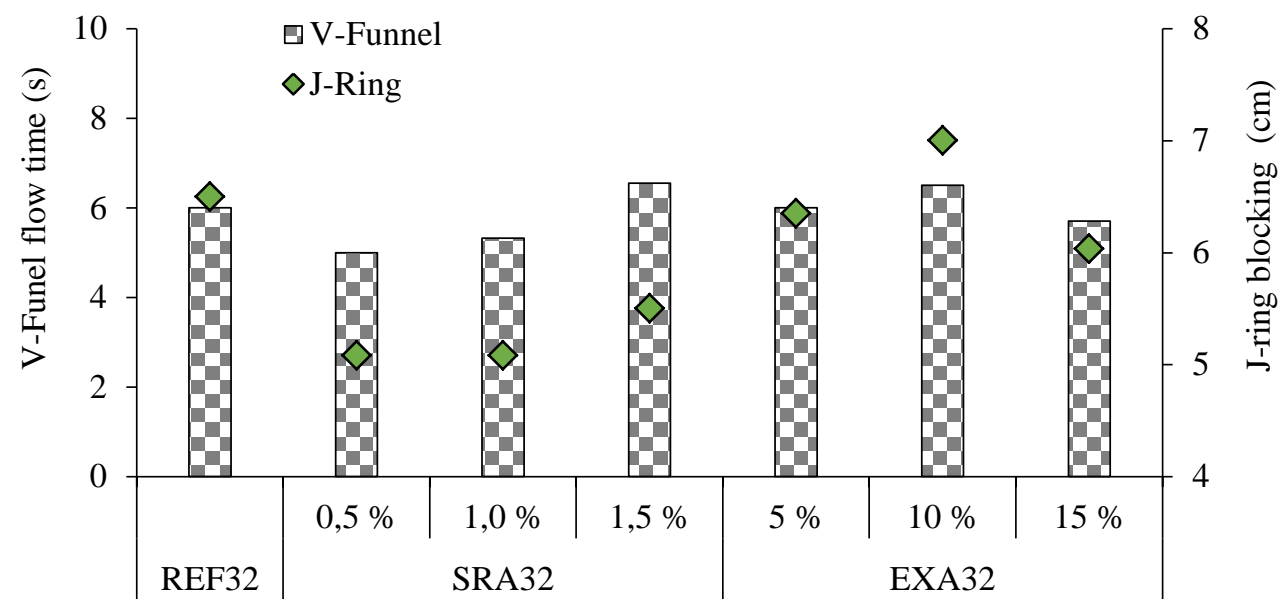

Figure 4: V-Funnel time and J-Ring blocking of HPSCC with SRA, EXA, and Reference.

The torque $(\mathrm{Nm})$ and rotational speed (rev/s) obtained from the rheometer for all studied mixtures are presented in

Figure 5.a-g and the rheological properties in fundamental units in Table 4. The results at 10 min show the same trend as the empirical tests results, with similar rheological behavior between samples (Figures 6, 7 and 8). The similarity in rheological behavior at $10 \mathrm{~min}$ of mixtures with EXA, SRA, and Reference mix can be explained by the lack of time for the chemical reactions to occur between EXA and water, which produce ettringite and calcium hydroxide, decreasing free water [7]. However, mixtures with EXA revealed a gradual increase of dynamic yield stress and of plastic viscosity (by Bingham model) over time, result of the abovementioned chemical reactions involving EXA, as shown in Table 4. In contrast with EXA, SRA does not consume water, it only reduces the surface tension of the pores solution [41]. This can be an explanation for the lesser variation of rheological properties shown by mixtures with SRA, which showed a plateau for rheological parameter after 25 minutes. Moreover, in some cases, the use of SRA has shown an increase of initial setting time of concrete [14]. The results suggest that the SRA can be added together with EXA for reduced slump flow loss. Likewise, a hydration stabilizer agent can be used.

Although all the mixtures showed a similar behavior to empirical and rheological tests, it has not been possible to find a correlation between slump flow diameter and dynamic yield stress for all the rheological models. Initially, it was hypothesized that this happened due to the thickness of the sample at flow stoppage, which should be at least five times the diameter of the largest aggregate to be able to consider the flow of an homogeneous mixture [21], but as Roussel [42] showed, there is no direct correlation between yield stress and slump flow diameter. 


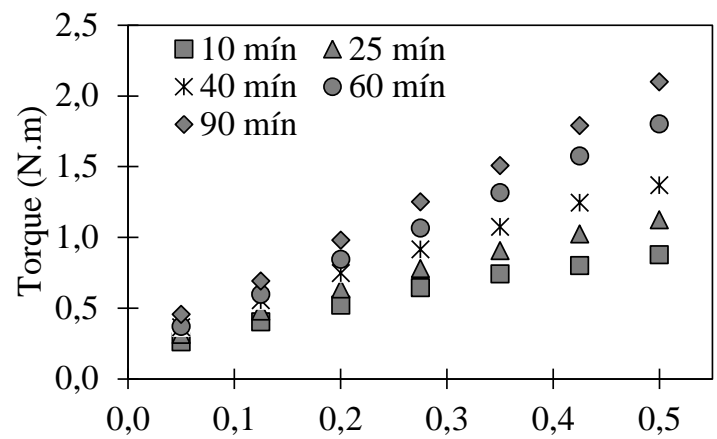

(a)
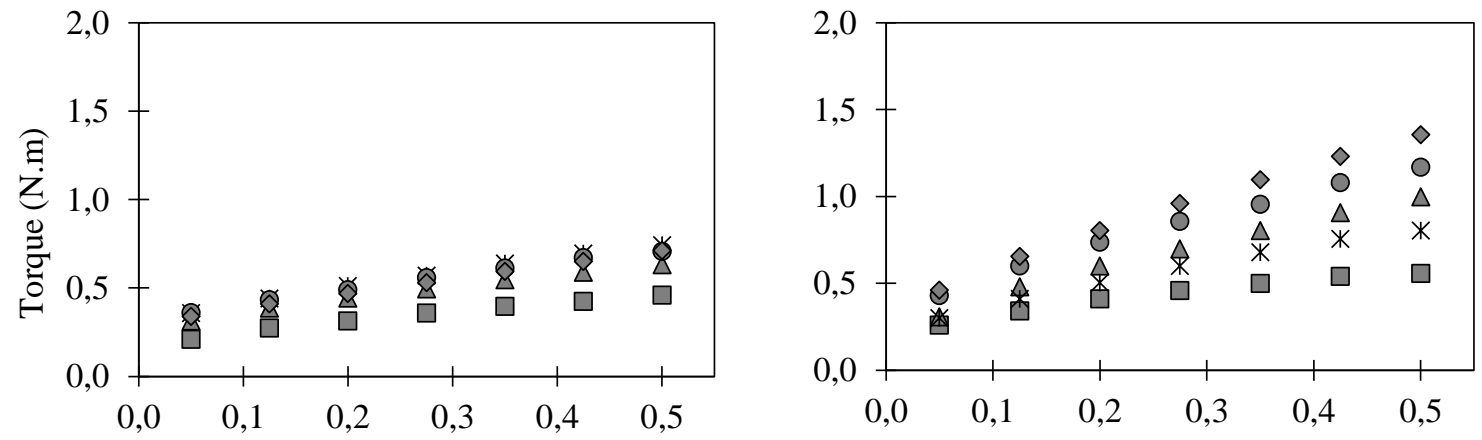

(b)

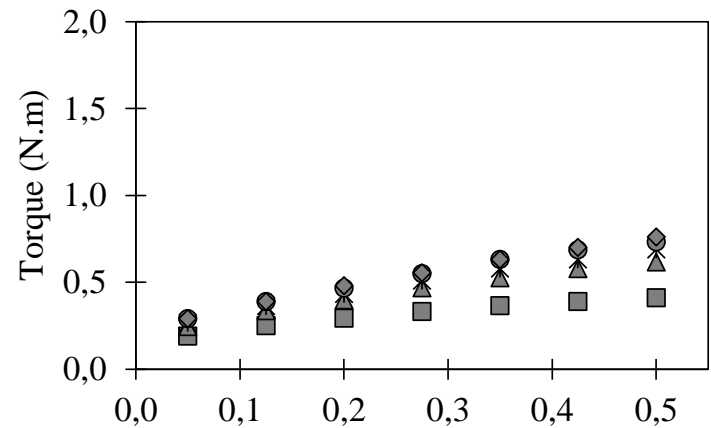

(c)

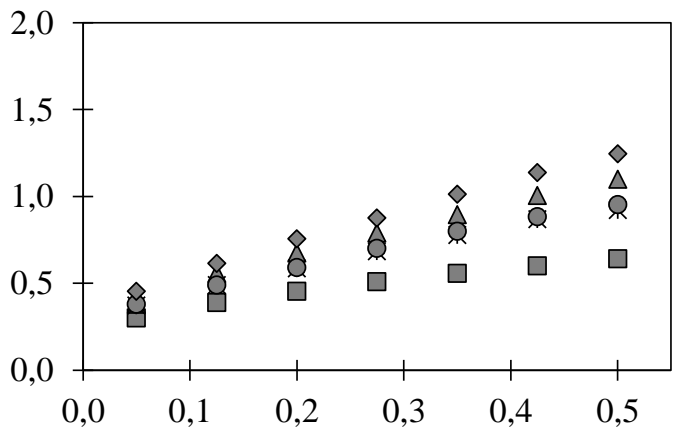

(d)

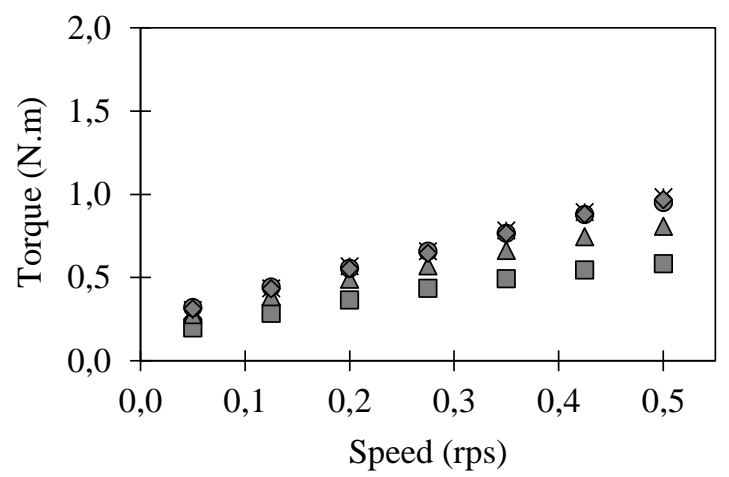

(f)

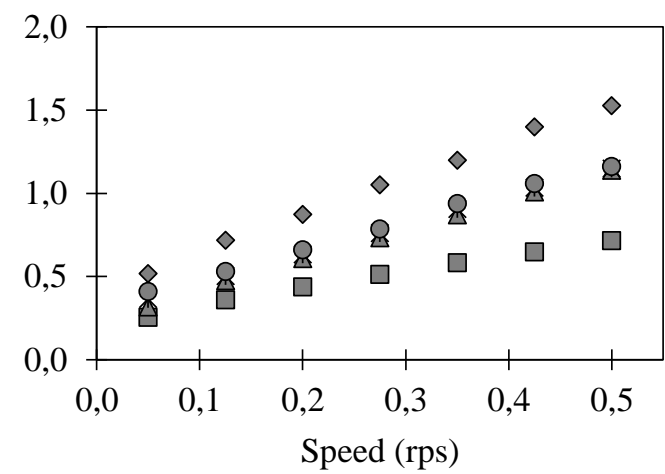

(g)

Figure 5: Torque versus rotational speed obtained from the rheometer for the reference concrete (a), mixtures with SRA $0.5 \%$ (b), $1.0 \%$ (d) and 1.5\% (f); EXA 5\% (c), $10 \%$ (e) and 15\% (g). 
Table 4: Rheological parameters.

\begin{tabular}{|c|c|c|c|c|c|c|c|c|c|}
\hline \multirow{2}{*}{\multicolumn{2}{|c|}{$\begin{array}{l}\text { RHEOLOGICAL } \\
\text { PARAMETERS }\end{array}$}} & \multirow{3}{*}{$\frac{\text { Time }}{(\mathbf{m i n})}$} & \multirow[t]{2}{*}{ REF32 } & \multicolumn{3}{|c|}{ SRA32 } & \multicolumn{3}{|c|}{ EXA32 } \\
\hline & & & & $0,5 \%$ & $1,0 \%$ & $1,5 \%$ & $5 \%$ & $10 \%$ & $15 \%$ \\
\hline \multirow{10}{*}{ 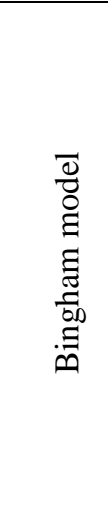 } & \multirow{5}{*}{ 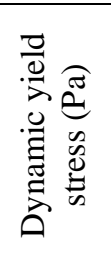 } & & 24,5 & 21,3 & 19,9 & 18,9 & 27,5 & 31,1 & 24,1 \\
\hline & & 25 & 27,0 & 31,6 & 24,2 & 25,2 & 29,4 & 36,7 & 25,5 \\
\hline & & 40 & 29,5 & 35,4 & 25,7 & 26,3 & 28,6 & 35,4 & 30,0 \\
\hline & & 60 & 21,4 & 35,7 & 28,1 & 28,0 & 41,4 & 35,2 & 34,4 \\
\hline & & 90 & 22,8 & 32,5 & 27,5 & 26,4 & 42,3 & 41,6 & 45,2 \\
\hline & \multirow{5}{*}{ 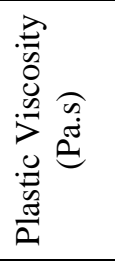 } & 10 & 20,3 & 8,0 & 7,2 & 12,8 & 9,8 & 10,9 & 14,9 \\
\hline & & 25 & 26,9 & 10,4 & 12,3 & 17,6 & 22,2 & 23,2 & 26,9 \\
\hline & & 40 & 33,4 & 12,7 & 13,8 & 22,4 & 16,8 & 18,4 & 26,1 \\
\hline & & 60 & 47,6 & 11,6 & 14,8 & 21,1 & 24,1 & 19,2 & 25,4 \\
\hline & & 90 & 68,1 & 12,2 & 15,5 & 21,8 & 29,3 & 26,1 & 33,4 \\
\hline \multirow{15}{*}{ 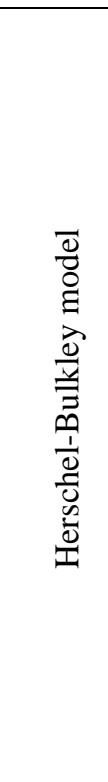 } & \multirow{5}{*}{ 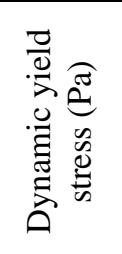 } & 10 & 3,8 & 14,2 & 7,6 & 5,9 & 4,9 & 16,9 & 16,6 \\
\hline & & 25 & 12,7 & 25,1 & 13,9 & 16,7 & 14,0 & 21,6 & 23,1 \\
\hline & & 40 & 19,1 & 29,2 & 17,7 & 20,5 & 16,8 & 26,9 & 28,3 \\
\hline & & 60 & 24,0 & 30,3 & 17,4 & 22,6 & 26,2 & 28,5 & 33,4 \\
\hline & & 90 & 32,5 & 31,3 & 19,5 & 23,7 & 30,0 & 34,2 & 40,7 \\
\hline & \multirow{5}{*}{ 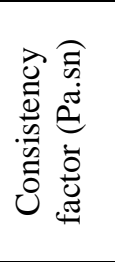 } & 10 & 46,2 & 16,9 & 22,9 & 29,0 & 39,6 & 28,8 & 24,1 \\
\hline & & 25 & 44,4 & 18,3 & 25,0 & 28,0 & 41,1 & 41,7 & 29,7 \\
\hline & & 40 & 45,9 & 20,2 & 23,6 & 29,3 & 31,3 & 28,8 & 28,1 \\
\hline & & 60 & 44,5 & 18,2 & 27,8 & 27,6 & 42,7 & 27,4 & 26,6 \\
\hline & & 90 & 47,4 & 13,5 & 25,2 & 25,1 & 44,2 & 34,9 & 38,8 \\
\hline & \multirow{5}{*}{ 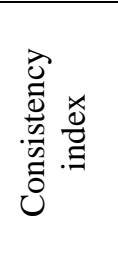 } & 10 & 0,59 & 0,62 & 0,46 & 0,59 & 0,39 & 0,53 & 0,74 \\
\hline & & 25 & 0,73 & 0,70 & 0,63 & 0,75 & 0,68 & 0,69 & 0,94 \\
\hline & & 40 & 0,82 & 0,75 & 0,71 & 0,85 & 0,67 & 0,76 & 0,96 \\
\hline & & 60 & 1,04 & 0,75 & 0,67 & 0,85 & 0,70 & 0,80 & 0,97 \\
\hline & & 90 & 1,08 & 0,94 & 0,74 & 0,92 & 0,77 & 0,84 & 0,91 \\
\hline \multirow{15}{*}{ 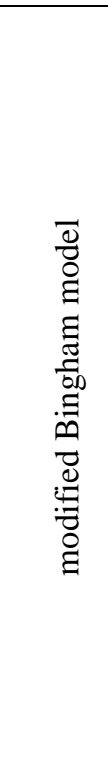 } & \multirow{5}{*}{ 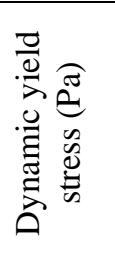 } & 10 & 16,6 & 18,7 & 16,3 & 13,9 & 21,7 & 26,7 & 21,0 \\
\hline & & 25 & 20,4 & 28,9 & 20,2 & 21,3 & 23,8 & 30,9 & 24,5 \\
\hline & & 40 & 24,2 & 32,6 & 22,3 & 23,5 & 23,4 & 31,3 & 28,9 \\
\hline & & 60 & 22,9 & 32,8 & 23,4 & 25,1 & 35,3 & 31,6 & 33,4 \\
\hline & & 90 & 31,7 & 31,9 & 24,0 & 24,9 & 36,8 & 38,0 & 42,9 \\
\hline & \multirow{5}{*}{ 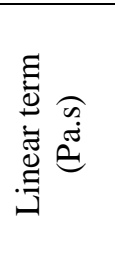 } & 10 & 31,8 & 11,7 & 12,3 & 20,1 & 18,0 & 17,3 & 19,3 \\
\hline & & 25 & 36,5 & 14,2 & 18,1 & 23,3 & 30,3 & 31,5 & 28,4 \\
\hline & & 40 & 41,1 & 16,6 & 18,8 & 26,6 & 24,3 & 24,4 & 27,6 \\
\hline & & 60 & 45,5 & 15,4 & 21,5 & 25,3 & 32,8 & 24,5 & 26,9 \\
\hline & & 90 & 55,3 & 13,0 & 20,6 & 24,0 & 37,2 & 31,2 & 36,7 \\
\hline & \multirow{5}{*}{ 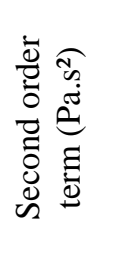 } & 10 & $-2,7$ & $-0,9$ & $-1,2$ & $-1,7$ & $-2,0$ & $-1,5$ & $-1,1$ \\
\hline & & 25 & $-2,3$ & $-0,9$ & $-1,4$ & $-1,4$ & $-1,9$ & $-2,0$ & $-0,4$ \\
\hline & & 40 & $-1,8$ & $-0,9$ & $-1,2$ & $-1,0$ & $-1,8$ & $-1,4$ & $-0,4$ \\
\hline & & 60 & 0,5 & $-0,9$ & $-1,6$ & $-1,0$ & $-2,1$ & $-1,2$ & $-0,4$ \\
\hline & & 90 & 3,0 & $-0,2$ & $-1,2$ & $-0,5$ & $-1,9$ & $-1,2$ & $-0,8$ \\
\hline
\end{tabular}

In general, the dynamic yield stress values obtained by Bingham model were the highest, followed by values found for the modified Bingham and Herschel-Bulkley models. This is due to the mixtures adjusted by the non-linear models exhibiting a shear thinning behavior, except the reference mixture at 60 and 90 min, as shown in Figures 9 and 10. 


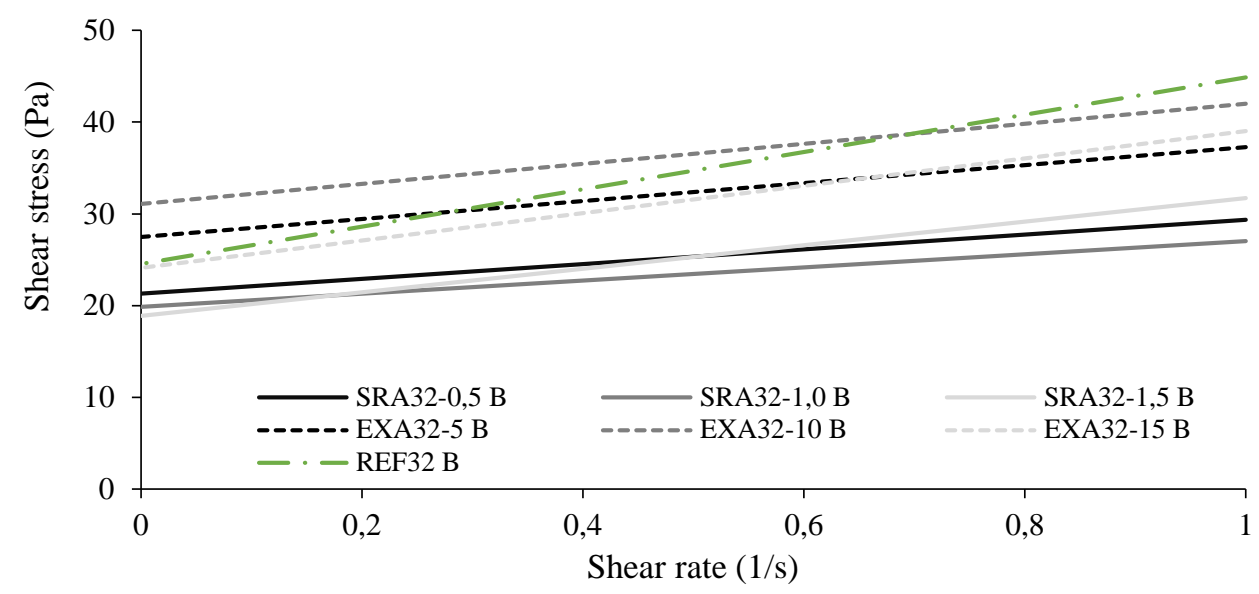

Figure 6: Application of the Bingham model on the rheological data at $10 \mathrm{~min}$ for of HPSCC with SRA $(0.5 \% ; 1.0 \%$; $1.5 \%)$, EXA $(5 \% ; 10 \% ; 15 \%)$ and Reference concrete.

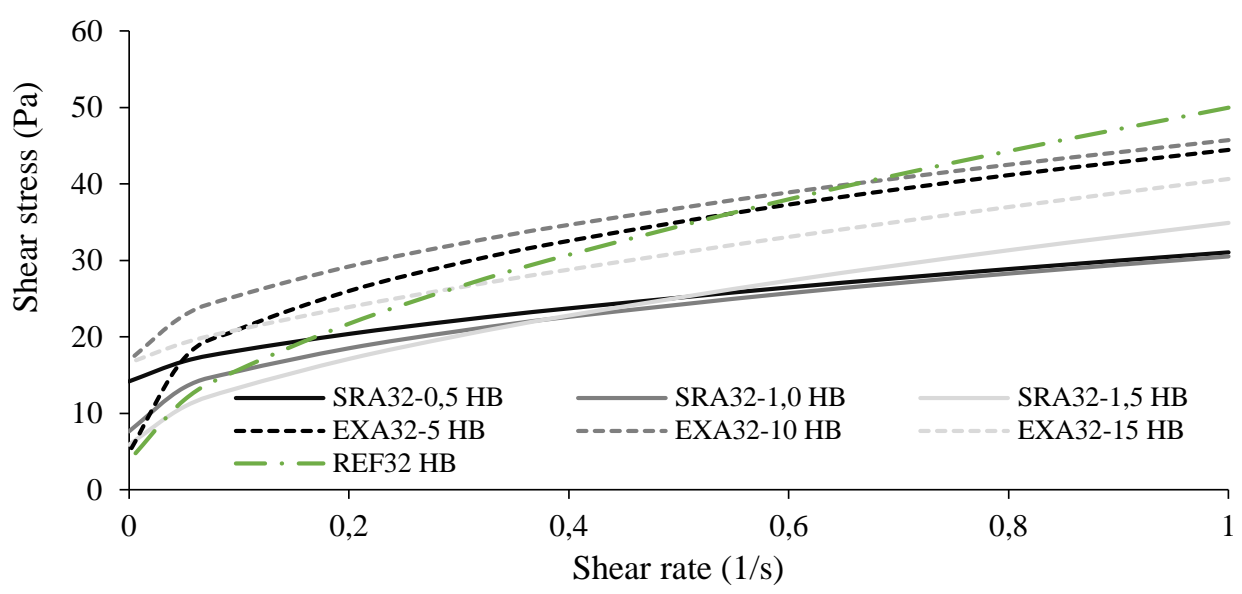

Figure 7: Application of the Herschel-Bulkley model on the rheological data at $10 \mathrm{~min}$ for of HPSCC with SRA $(0.5 \%$; $1.0 \% ; 1.5 \%)$, EXA $(5 \% ; 10 \% ; 15 \%)$ and Reference concrete.

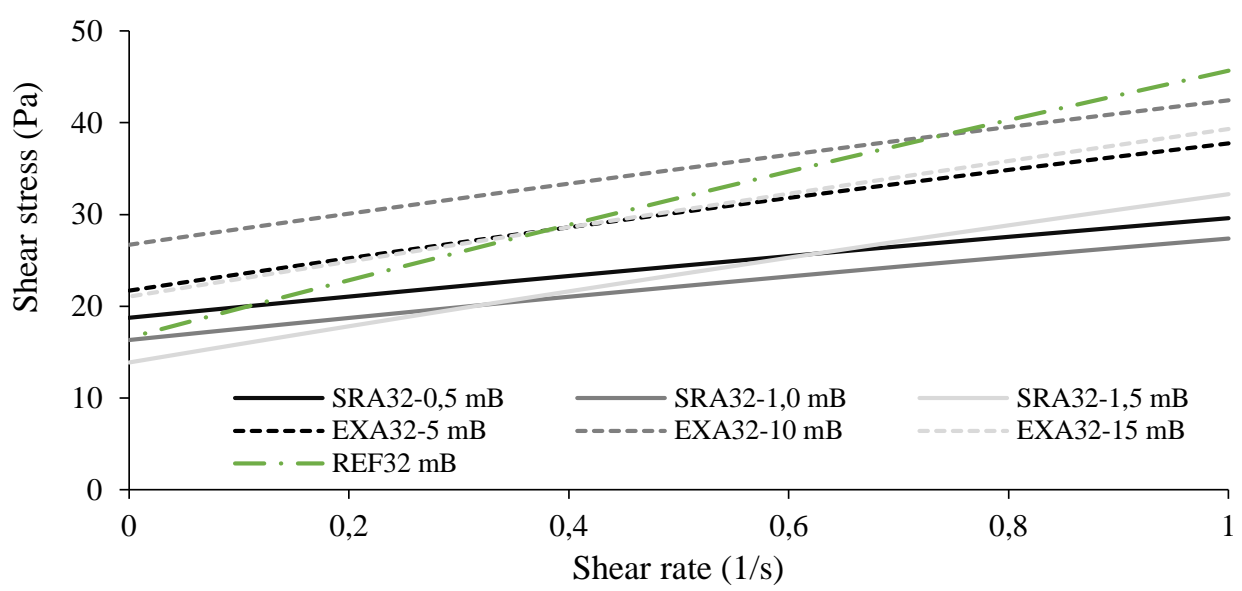

Figure 8: Application of modified Bingham model on the rheological data at $10 \mathrm{~min}$ for of HPSCC SRA $(0.5 \%$; $1.0 \%$; $1.5 \%)$, EXA ( $5 \% ; 10 \% ; 15 \%)$ and Reference concrete. 


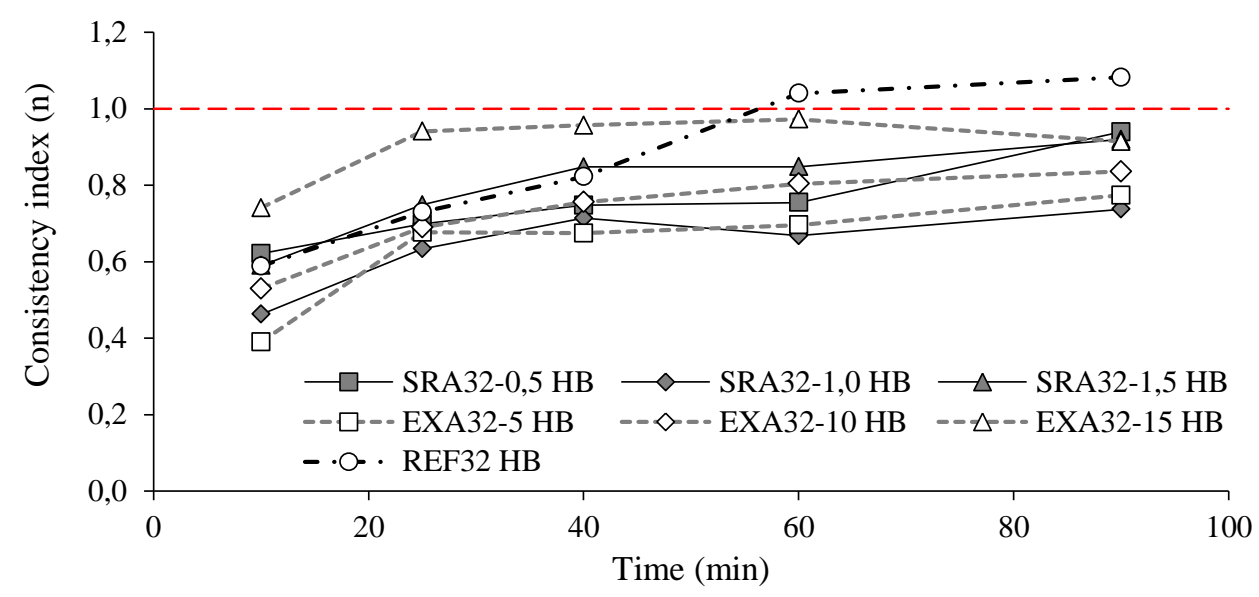

Figure 9: Consistency index for mixtures with SRA $(0.5 \% ; 1.0 \% ; 1.5 \%)$, EXA $(5 \% ; 10 \% ; 15 \%)$ and reference concrete.

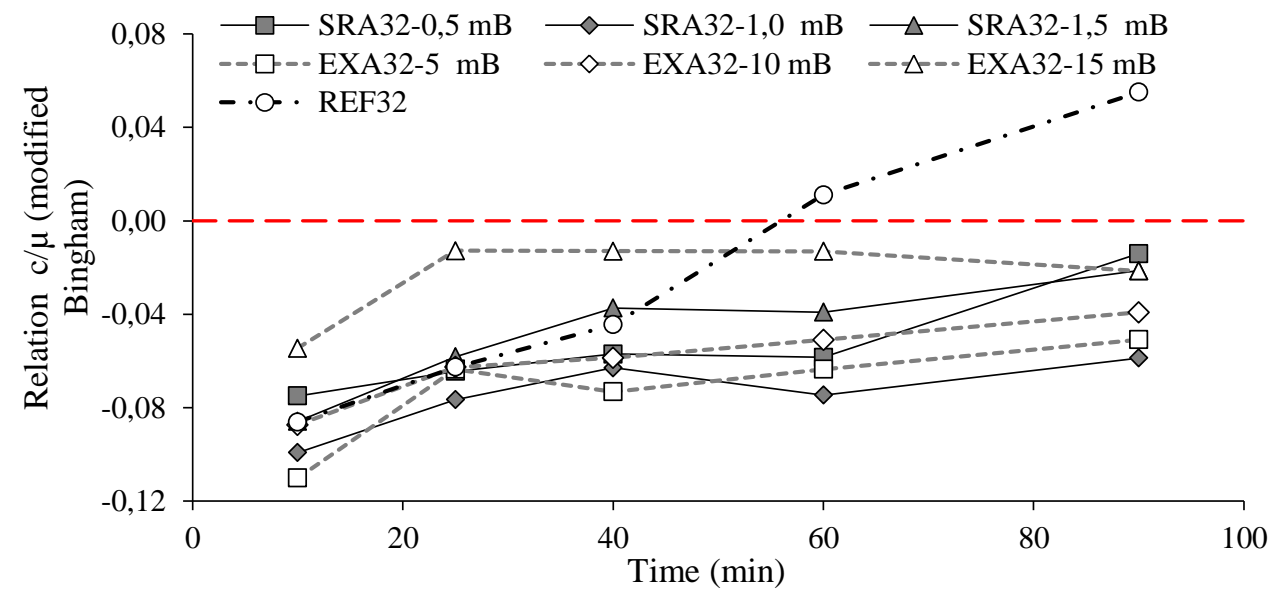

Figure 10: relation $c / \mu$ for mixtures with SRA $(0.5 \% ; 1.0 \% ; 1.5 \%)$, EXA $(5 \% ; 10 \% ; 15 \%)$ and reference concrete.

Analysis of variance (ANOVA) was performed to pinpoint the individual effects of factors (type of admixture, admixture content and test time) on the dependent variable. Second order interactions could not be verified, since there was no repetition of concrete. The results of ANOVA for rheological results are presented in Table 5. A factor was considered to have significant effect on the rheological parameters when the Probability was more than $95 \%$ (confidence level).

Regardless of the rheological model adopted, the admixture content is not an important factor for the yield stress. On the other hand, the type of admixture and the teste time are equally important. The parameters that determine shear-thinning behavior in HB and modified Bingham models (consistency index and $c / \mu$, respectively), are not influenced by the type of additive present, with $95 \%$ confidence level. However, the other factors (admixture content and time) are very important for the rheological results of the mixtures. In addition, it can be verified that all the factors are influential in the viscosity (determined by the Bingham model). 
Table 5: ANOVA for rheological results.

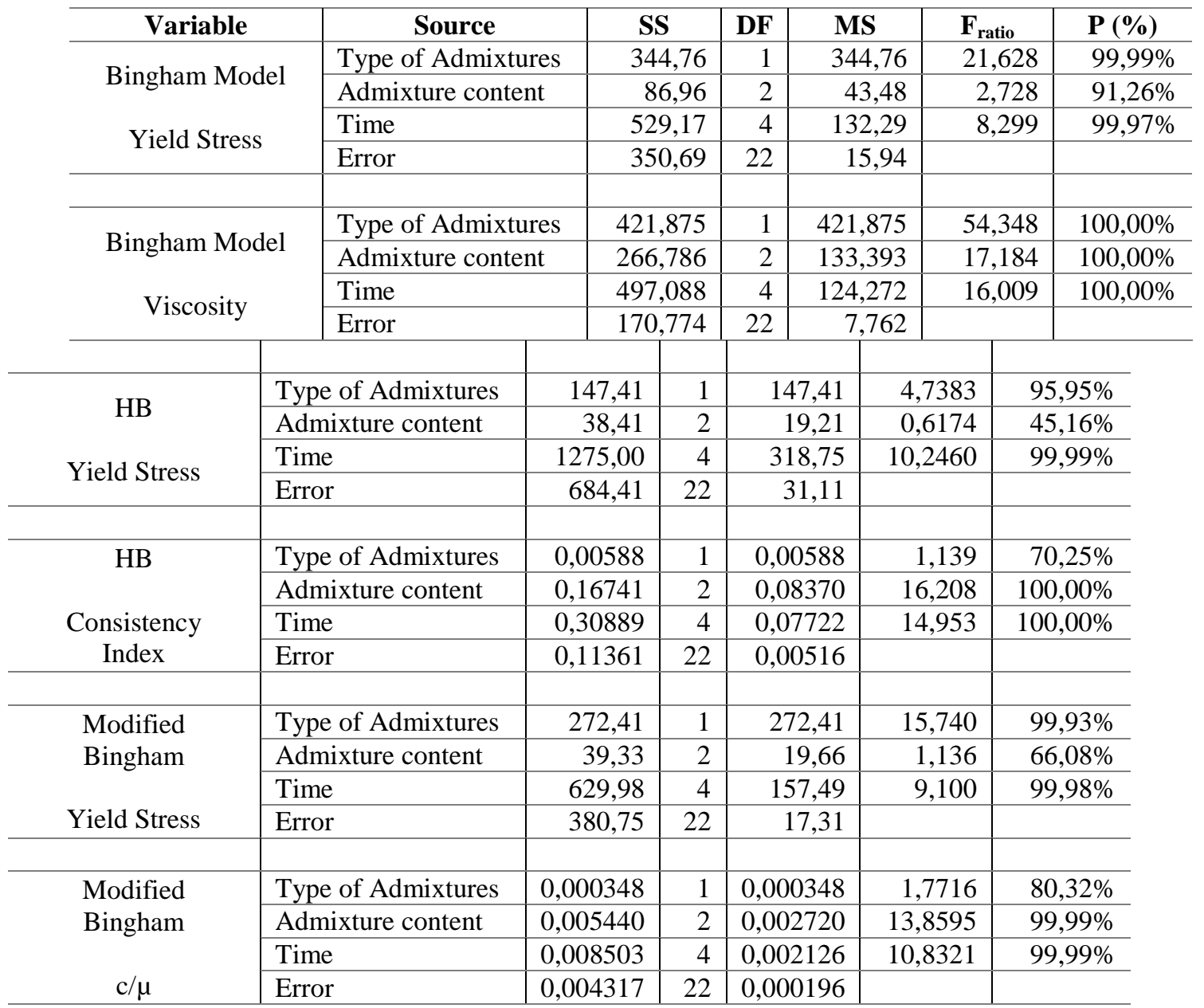

SS: sum of squares; DF: degree of freedom; MS: mean square; Fratio: F-statistic (source/error); P: probability.

\section{CONCLUSION}

This paper demonstrated that high performance self-compacting concrete can be designed with SRA and EXA without major damage to the rheological properties of the mixtures. All the mixtures studied can be classified as SCC even at 90 min after started the mix. This was possible by the high dosage of superplasticizer used to reach the target slump flow diameter between 650 and $690 \mathrm{~mm}$. The mixture with $10 \%$ of expansive admixture required the highest dosages of superplasticizer. Concrete with expansive admixture showed a gradual increase of dynamic yield stress and a slump flow loss over time. The addition of SRA in HPSCC had little influence in the rheological behavior of the mixtures over time. The results suggest that the SRA can be added together with EXA for reduced slump flow loss.

\section{ACKNOWLEDGEMENT}

A Coordenação de Aperfeiçoamento de Pessoal de Nível Superior - CAPES (99999.008307/2014-08).

ANEEL, Projeto UFSC- CESP n. PD-0061-0001/2010

FAPESC-CNPq Projeto PRONEX

University of Texas at Austin - USA.

\section{BIBLIOGRAPHY}

[1] MEHTA, P., AÏTCIN, P.-C. "Principles Underlying Production of High-Performance Concrete", Cem. Concr. Aggregates, v 12, n. 2, pp 70-78, 1990.

[2] OKAMURA,H., OUCHI, M. "Self-Compacting Concrete", J. Adv. Concr. Technol., v. 1, pp. 5-15, April, 2003. 
[3] AÏTCIN, P.C. High-Performance Concrete, $2^{\text {nd }}$ ed, London, E\& FN SPON, 2004.

[4] JENSEN, O.M., HANSEN, P.F. "Autogenous deformation and RH-change in perspective", Cem. Concr. Res., v. 31, pp. 1859-1865, Dec. 2001.

[5] TAZAWA, E., MIYAZAWA, S. "Experimental study on mechanism of autogenous shrinkage of concrete", Cem. Concr. Res., v. 25, pp. 1633-1638. Dec. 1995.

[6] MAILVAGANAM, N.P. "Miscellaneous Admixtures", In: Concr. Admixtures Handb., $2^{\text {nd }}$ ed, c. 15, Canada, WA Publications, pp. 939-1024, 1996.

[7] NAGATAKI, S., GOMI, H. "Expansive admixtures (mainly ettringite)", Cem. Concr. Compos., v. 20 pp. 163-170. Mar.1998.

[8] REPETTE, W. L., MAILVAGANAM, N. P. "Calcium sulphoaluminate based expansive admixtures - A Re-view". In: Proceedings of Seventh CANMET/ACI International Conference on Superplasticizers and other Admixtures in Concrete, p. 177-198, Berlin. Proceedings. ACI-SP-217, v. 1. American Concrete Institute, October, 2003.

[9] REPETTE, W. L., MAILVAGANAM, N. P. "Pre-hydrated high alumina cement based admixture for compensating autogenuos shrinkage in HPC". In: Proceedings of Second CANMET/ACI International Conference on High Performance Concrete. Pp. 39-57. Gramado, Brasil. Proceedings: Second CANMET/ACI International Conference - ACI SP 186. Gramado. 1999.

[10] HUA, C., ACKER, P., EHRLACHER, A. "Analyses and models of the autogenous shrinkage of hardening cement paste. I. Modelling at macroscopic scale", Cem. Concr. Res.,v. 25, n.7, pp.1457-1468, Oct.1995.

[11] BENTZ, D.P. “A review of early-age properties of cement-based materials”, Cem. Concr. Res., v. 38 pp. 196-204, Feb. 2008.

[12] GAGNÉ, R. Shrinkage-reducing admixtures, In: Science and Technology of Concrete Admixtures, 1st ed., c. 23, UK, Woodhead Publishing, pp. 457-469, 2016.

[13] SHOYA, M., SUGITA, S., SUGAWARA, T. "Improvement of drying shrinkage and shrinkage cracking of concrete by special surfactants", In: Admixtures Concr. Improv. Prop., 1st ed., c. 5, Barcelona, RILEM, pp. 521-541, 1990

[14] FOLLIARD, K.J., BERKE, N.S. "Properties of high-performance concrete containing shrinkagereducing admixture", Cem. Concr. Res., v. 27, n.9, pp. 1357-1364, Sept. 1997.

[15] RONGBING, B., JIAN, S. "Synthesis and evaluation of shrinkage-reducing admixture for cementitious materials", Cem. Concr. Res., v.35, n. 3, pp. 445-448, Mar. 2005.

[16] MORA-RUACHO, J., GETTU, R., AGUADO, A. "Influence of shrinkage-reducing admixtures on the reduction of plastic shrinkage cracking in concrete", Cem. Concr. Res., v. 39, n. 3, pp.141-146. Mar. 2009.

[17] WYRZYKOWSKI, M., TRTIK, P., MÜNCH, B., et al., "Plastic shrinkage of mortars with shrinkage reducing admixture and lightweight aggregates studied by neutron tomography", Cem. Concr. Res., v. 73, pp. 238-245. Jul. 2015.

[18] YAHIA, A., MANTELLATO, S., FLATT, R.J. "Concrete rheology: a basis for understanding chemical admixtures", In: Science and Technology of Concrete Admixtures, $1^{\text {st }}$ ed., c. 7, UK, Woodhead Publishing, pp 97-127, 2016.

[19] WALLEVIK, O.H., WALLEVIK, J.E. "Rheology as a tool in concrete science: The use of rheographs and workability boxes", Cem. Concr. Res., v. 41, n. 12, pp. 1279-1288. Dec. 2011

[20] NGUYEN, T.L.H., ROUSSEL, N., COUSSOT, P. "Correlation between L-box test and rheological parameters of a homogeneous yield stress fluid", Cement and Concrete Research, v. 36, n.10, pp. 1789-1796, Oct. 2006.

[21] ROUSSEL, N. "From industrial testing to rheological parameters for concrete", In: Underst. Rheol. Concr., $1^{\text {st }}$ ed., c. 4, UK, Woodhead Publishing, pp. 83-95, 2012.

[22] TATTERSALL, G.H., BANFILL, P.F.G. The rheology of fresh concrete, $1^{\text {st }}$ ed., London, Pitman advanced Publishing. 1983.

[23] TATTERSALL, G.H. Workability and quality control of concrete, $1^{\text {st }}$ ed. London, Spon, 1991.

[24] FERRARIS, C.F. "Measurement of the rheological properties of high performance concrete: State of the art report", J. Res. Natl. Inst. Stand. Technol., v. 104, n.5, pp. 461-478., Setp. 1999.

[25] YAHIA, A., KHAYAT, K.H. "Analytical models for estimating yield stress of high-performance pseudoplastic grout”, Cem. Concr. Res., v. 31, n. 5, pp. 731-738, May 2001. 
[26] FEYS, D., WALLEVIK, J.E., YAHIA, A., et al., "Extension of the Reiner-Riwlin equation to determine modified Bingham parameters measured in coaxial cylinders rheometers", Mater. Struct., v. 46, pp. $289-311$. Jul. 2013

[27] FRIDTJOV, I. Continuum Mechanics, $1^{\text {st }}$ ed., Noruega, Springer, 2008.

[28] WALLEVIK, O.H., FEYS, D., WALLEVIK, J.E., et al., “Avoiding inaccurate interpretations of rheological measurements for cement-based materials”, Cem. Concr. Res., v. 78, pp.100-109, Dec. 2015

[29] GÜNEYISI, E., GESOGLU, M., AL-GOODY, A., et al., "Fresh and rheological behavior of nano-silica and fly ash blended self-compacting concrete", Constr. Build. Mater., v. 95, pp. 29-44, Oct. 2015

[30] ASTM C 845, Standard specification for expansive hydraulic cement, ASTM Int. 4, 1-3, 2012.

[31] ASTM C 1611, Standard test method for slump flow of self-consolidating concrete, ASTM Int.,1-6, 2014.

[32] ASTM C 1621, Standard test method for passing ability of self-consolidating concrete by J-ring, ASTM Int. 5., 2014.

[33] EFNARC, The European Guidelines for Self-Compacting Concrete, Eur. Guidel. Self Compact. Concr. 2005.

[34] SAAK, A.W., JENNINGS, H.M., SHAH, S.P. "The influence of wall slip on yield stress and viscoelastic measurements of cement paste”, Cem. Concr. Res., v. 31, n. 2, pp. 205-212, Feb. 2001.

[35] BILLBERG, P. "Understanding formwork pressure generated by fresh concrete", In: Underst. Rheol. Concr., $1^{\text {st }}$ ed., c. 12, UK, Woodhead Publishin, pp. 296-330.

[36] HEIRMAN, G., VANDEWALLE, L., VAN GEMERT, D., et al., "Integration approach of the Couette inverse problem of powder type self-compacting concrete in a wide-gap concentric cylinder rheometer, J. Nonnewton." Fluid Mech., v. 150, n.2-3, pp. 93-103, April 2008.

[37] HEIRMAN, G., HENDRICKX, R., VANDEWALLE, L., et al., "Integration approach of the Couette inverse problem of powder type self-compacting concrete in a wide-gap concentric cylinder rheometer: Part II. Influence of mineral additions and chemical admixtures on the shear thickening flow behaviour", Cem. Concr. Res., v. 39, n. 3, pp. 171-181, March 2009.

[38] FEYS, D., VERHOEVEN, R., SCHUTTER, G. "Fresh self compacting concrete, a shear thickening material”, Cem. Concr. Res., v. 38, n. 7, pp. 920-929, Jul. 2008.

[39] LU, C., YANG, H., MEI, G. "Relationship between slump flow and rheological properties of self compacting concrete with silica fume and its permeability”, Constr. Build. Mater., v. 75, pp157-162, Jan. 2015.

[40] NAJIM, K.B., AL-JUMAILY, I., ATEA, A.M. "Characterization of sustainable high performance / self-compacting concrete produced using CKD as a cement replacement material”, Constr. Build. Mater., v.103, pp. 123-129, Jan. 2016.

[41] EFNARC, Specification and Guidelines for Self-Compacting Concrete, Eur. Guidel. Self Compact. Concr. 44, 2005.

[42] LURA, P., PEASE, B., MAZZOTTA, G.B., et al., "Influence of Shrinkage-Reducing Admixtures on Development of Plastic Shrinkage Cracks”, ACI Mater. J., v. 104, pp. 187-194, Jan. 2007

[43] ROUSSEL, N. "The LCPC BOX: a cheap and simple technique for yield stress measurements of SCC", Mater. Struct., v. 40, n.9, pp. 889-896, Nov. 2007. 